\title{
PERCEIVING NECESSITY
}

BY

\section{CATHERINE LEGG AND JAMES FRANKLIN}

\begin{abstract}
In many diagrams one seems to perceive necessity - one sees not only that something is so, but that it must be so. That conflicts with a certain empiricism largely taken for granted in contemporary philosophy, which believes perception is not capable of such feats. The reason for this belief is often thought well-summarized in Hume's maxim: 'there are no necessary connections between distinct existences'. It is also thought that even if there were such necessities, perception is too passive or localized a faculty to register them. We defend the perception of necessity against such Humeanism, drawing on examples from mathematics.
\end{abstract}

\section{Examples of diagrams in which necessity is perceived}

We may gain knowledge that $2 \times 3=3 \times 2$ not by rote but by looking at the diagram:

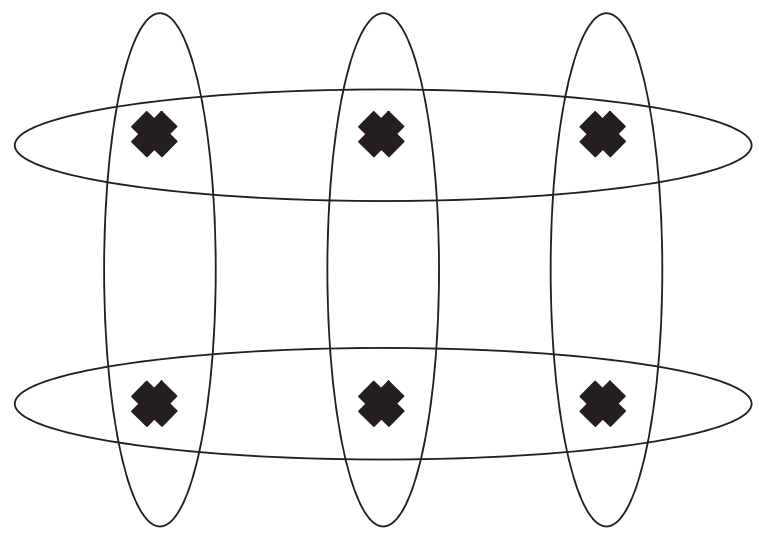

Figure 1 Why $2 \times 3=3 \times 2$.

Pacific Philosophical Quarterly 98 (2017) 320-343 DOI: 10.1111/papq.12133

(C) 2015 The Authors

Pacific Philosophical Quarterly (C) 2015 University of Southern California and John Wiley \& Sons Ltd. 
What is being perceived in this case? We are not just perceiving that $2 \times 3$ is $3 \times 2$, but that $2 \times 3$ must be $3 \times 2$. It is clear that to try to create another option - such as $2 \times 3=3 \times 3$ - would be futile. It is as though we can see the truth and at the same time the reason why it must be true. ${ }^{1}$ It therefore appears that, at least in the case of mathematics, we may perceive necessary truth.

What has just been said typically attracts many objections. What does it mean to see a reason? Surely reasons are more stated or understood than seen. Didn't key cases in 19th century mathematics show that deriving mathematical results from visual intuition risks wholescale error? ${ }^{2}$ While mathematics as an a priori science does seem to possess a particular perspicuousness, couldn't that rather be because it involves reasoning using unusually explicit chains of inference, and particularly compelling premises? Might not the apparent directness of our mathematical insight cover up an unconscious process of inference whereby we rule out other possibilities? In any case, would not perception of necessity involve seeing necessary connections between distinct existences, something shown impossible by Hume? And surely, even if there were such necessary connections to be known, perception is too simple (or, frankly, too stupid) a faculty to perceive them? Moreover, even if it is correct to say that we 'intuit' necessity, is this not necessity in some abstract Platonic realm, rather than this concrete world? Finally, is not any 'must-detecting' faculty (Blackburn, 1986) incompatible with naturalism?

One might ask whether mathematical necessity is only perceivable for relatively simple arithmetic truths concerning discrete, countable numbers of things easily gathered and inspected, as above. The answer is not strictly relevant to our thesis, which is merely that at least some diagrams allow the perception of necessity. However, a brief survey will provisionally indicate other areas of mathematics where necessity may be directly perceived.

Geometry traffics in irrational and continuously varying quantities, so one might worry that at least some of its necessary truths concern distinctions too fine for the naked eye to discern (for example that the ratio of a circle's circumference and diameter is $\pi$ ). However necessity may also be perceived in geometry. Giaquinto gives this simple example, similar to that in Plato's Meno (Figure 2). The inside square, in diamond orientation, has sides that connect the midpoints of the sides of the larger square. How much is the area of the outside, compared to the inside square? If we imagine folding in the four outer triangles, we see that they would cover the inner square exactly - therefore the larger square is twice its area (Giaquinto, 2007, fig. $4.1^{3}$ ). 


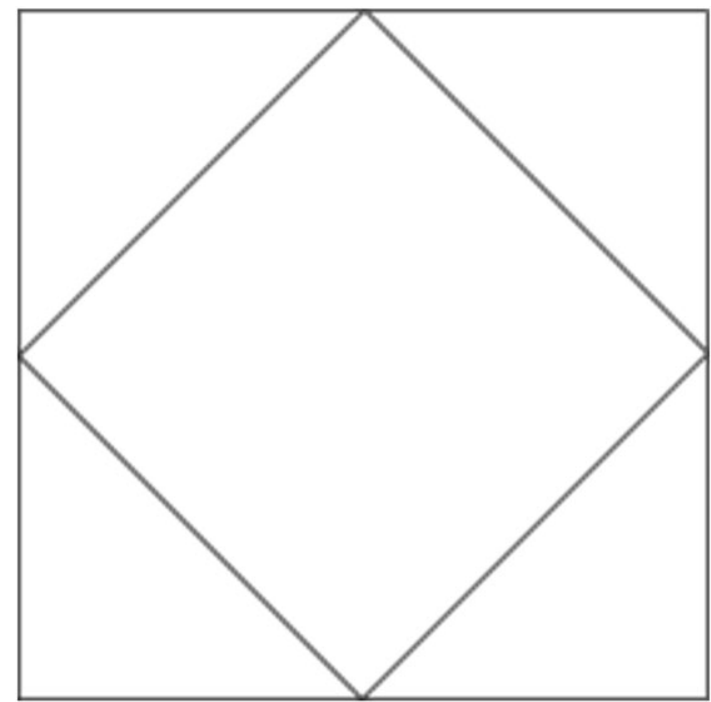

Figure 2 Why the Inside Square is Half the Outside Square.

Giaquinto (2007, pp. 28-29) argues - and we agree - that perception of this geometrical necessity does not depend on any infinitely precise perception of line-straightness or point-positioning. To use instruments to precisely measure sides and areas in order to 'verify' it would be beside the point. ${ }^{4}$ The visual sense is able to 'rectify' an approximate diagram and thereby see what must be so in the relations of two exact squares positioned as shown. Once again, some element of 'seeing the reason why it must be so' seems to guide this rectification process.

What about very abstract areas of mathematics such as higher analysis and transfinite mathematics? Surely here one must visualise infinitely large sets, which is impossible? However, certain examples suggest that it is even possible to perceive necessary truths that 'go to infinity'. Consider the diagram in Figure 3, which illustrates that the set of rational numbers has the same cardinality as the (countable) natural numbers.

This result was enormously counterintuitive, since the rational numbers are so thickly distributed on the real line. Cantor, who first proved it, famously wrote in a letter to Dedekind, of a closely related result, 'I see it but I don't believe it! ${ }^{5}$ Though by no means proving our thesis, it is worth noting how naturally Cantor reaches for visual language to express such crucial moments. Specifically, by means of the clever organization of the fractions in Figure 3 one can see that a progression through them has been defined so systematically that every rational number has a unique well-defined place in the sequence. This means that every whole number may be assigned one corresponding rational number, and vice versa. One is not viewing the entire 


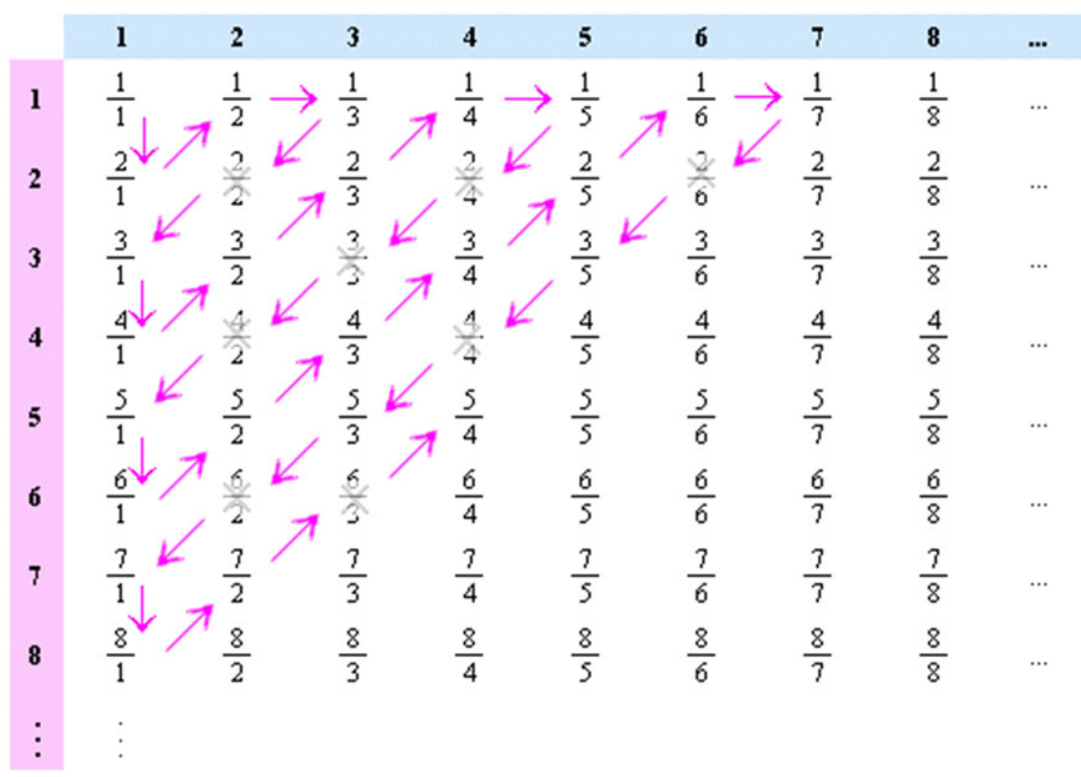

Figure 3 Why the Set of Rational Numbers is Countable. ${ }^{6}$ [Colour figure can be viewed at wileyonlinelibrary.com]

infinite sequence of natural-rational pairings, but one doesn't need to. One can already see that the correspondence has to be one-one, by seeing 'how it works' in some very general sense. ${ }^{7}$

Our project connects with a recent upsurge of interest in the role of diagrams in necessary reasoning: both in mathematics (Brown, 2008; Franklin, 2000; Giaquinto, 2007; Sherry, 2009a; Mumma, 2010; Catton and Montelle, 2012: many of these authors inspired by Manders, 2008) and in logic (Shin, 2002; Macbeth, 2005, 2009; Legg, 2012). This has been prompted by growing awareness that diagrams frequently serve as more than just post hoc illustration of necessary reasoning which has already taken place in some more 'serious' nondiagrammatic form. This movement has brought fresh perspectives to philosophy of mathematics and philosophical logic. However, we believe that, even more importantly, it holds profound implications for general epistemology which are currently blocked by fealty to a certain picture of perception descending largely from Hume. We aim to challenge that picture and open up that wider epistemological debate. We have chosen to focus on mathematical necessity first, as we believe it provides the clearest illustration of our thesis, but hope to extend the thesis to other forms of necessity, such as logical and physical, in future work.

The opposition which the Humean legacy offers to acceptance of our thesis includes ontological and epistemological dimensions. Profound ontological morals are often drawn from Hume's claim, 'there are no necessary 
connections between distinct existences'. This has been taken to imply that there are no such necessities 'out there', hence no possibility of perceiving them (Section 2). The epistemological dimension includes a thesis that perception is both passive - involving a 'registering' of the impact of actual individual physical objects on the sense organs (Section 3) - and atomistic such that ideas are only considered to be distinct - or even distinguishable - if fully separable in the imagination (Section 4). Together these claims are taken to imply the impossibility of perceiving anything modal. The final sections of this article provisionally indicate significant empirical inadequacy in this understanding of perception (Section 5), and show how the examples above escape it (Section 6), by enabling the mind to abstract (necessary connections) without separating (objects).

Before continuing, we will briefly clarify what we mean by 'perception' in our claim that necessity can be perceived. We intend a minimal and uncontroversial reading of this term: the direct acquisition of beliefs about reality through veridical operations of the senses without the assistance of deliberate mental actions such as imagining or explicit reasoning. Having said this, where exactly the boundaries lie between perception and other such mental actions is notoriously difficult to define. It is common to understand perception as opposed to cognition, with the two distinguished insofar as perception is objectual (I perceive a yellow chair) and cognition is propositional (I know that the chair is yellow). Or, to give another example, hearing a sound stream as divided into syllable-objects is perception, but understanding speech is not, as it requires higher cognition. We will see that much in Hume's philosophical legacy encourages this kind of non-cognitivism about perception. Yet such an approach fails to explain how mere perception of objects might give rise to knowledge of propositions (i.e. perceptual judgments). We prefer a different approach to distinguishing perception from other mental faculties, focussing on its forcedness compared to both freely imagining objects and musing on propositions. (This is why we state above: 'without the assistance of deliberate mental actions'.) Of course our approach in turn opens up some difficult issues about where the boundary lies between perception and deliberative (or 'higher') cognition. Those issues, which are relevant to our thesis, will be discussed further in Sections 5 and 6 .

Finally, by 'reality' we mean the everyday reality in which we move and live.

\section{2. 'No necessary connections between distinct existences': the claim and what it means}

In the next three sections we critique certain aspects of 'Humeanism' or the 'Humean legacy'. The focus is not on detailed exegetical scholarship so much 
as the impact of certain of Hume's famous dicta on pictures of necessity and of perception deeply embedded in contemporary analytic philosophy.

Hume famously asserts:

No connexions between distinct existences are ever discoverable among human understanding (Treatise, Appendix; Hume, 1739-40/1978).

and again:

There is no object, which implies the existence of any other if we consider these objects in themselves (Treatise, 1, III, vi).

and more expansively:

Any thing may produce any thing. Creation, annihilation, motion, reason, volition; all these may arise from one another, or from any other object we can imagine ... no objects are contrary to each other, but existence and non-existence (Treatise, 1, III, xv).

This conclusion that no objects are contrary but existence and non-existence is quite remarkable. How about the 'objects' black and white? Or more relevantly to our present purpose, equal and not equal?

The meaning of these claims clearly depends crucially on what is meant by 'existences', or 'objects'. If one means non-overlapping physical substances, such as tables in a room, that is one claim, for which no doubt good arguments could be mounted. But it seems Hume does not mean that, since 'creation', 'non-existence' and so on are not physical substances. And in Hume's most famous application of his principle, to causality, he does not mean physical substances either. In the famous scene where one billiard ball strikes another, all we strictly see, Hume argues, is that the first ball moves towards the second, and then touches it briefly, and then the second ball moves away from the first:

I turn my eye to two objects suppos'd to be plac'd in that relation [of cause and effect] ... I immediately perceive, that they are contiguous in time and place, and that the object we call cause precedes the other we call effect. In no one instance can I go any farther, nor is it possible for me to discover any third relation betwixt these objects (Treatise, 1, III, xiv).

Here Hume speaks as if the 'objects' are just the billiard balls themselves, but he is actually talking about their motions.

What, then, does count as 'objects' or 'existences' here? Properties and events must be allowed, if motions are to count. But then, what about the properties 'black' and 'white'? The events of 2 and 3 hours passing? Or, to return to mathematics, the 'objects' $\varnothing$ and $\{\varnothing\}$ ? Even if we restrict ourselves 
to the motions of billiard balls, it seems there are necessary connections between:

(1) The ball's being at position 0 at time 0

(2) The ball's being at position 1 at time 1

(3) The ball's having velocity 1 through the time interval $(0,1)$

Namely, 1 and 3 imply 2; 2 and 3 imply 1; 3 implies (1 if and only if 2 ). ${ }^{8}$ Such examples suggest that an inquisitive eye be turned also on the meaning of 'distinct'. Are the empty set and its singleton 'distinct'? They are not identical, but the former is an element of the latter, so it would seem that the latter cannot exist without it (if of course the two can be said to exist).

In an intricate and searching paper Jessica Wilson has pointed out that despite widespread approval of Hume's dictum in contemporary metaphysics it is very difficult to define an unambiguous version of it that is simultaneously not subject to obvious counterexample, reasonably in accord with intuition, and non-trivial, and which of these failings it ends up exemplifying depends a great deal on the interpretation given to 'distinct'. She explores a range of definitions, which she refers to as numerical distinctness, weak modal distinctness, spatiotemporal distinctness, mereological distinctness and strong modal distinctness (Wilson, 2010, pp. 5-11). Considering many different permutations of these definitions with different interpretations of 'necessary', she concludes overall that weaker versions of the dictum are analytically true and thus unsuitable for doing any metaphysical work, while stronger versions are highly questionable.

Problems of this kind have been surprisingly little noticed. A certain Humean Modal Combinatorialism, as it might be called, has had enormous downstream philosophical influence. We name the claim thus as it holds that 'objects' (in Hume's terms) are all compossible; in other words, objects possess no properties which rule out that they may be combined with one another in any way whatsoever. It is also found in Wittgenstein's Tractatus, ${ }^{9}$ which strongly influenced Carnap's treatment of necessity as truth in all 'statedescriptions': complete permutations of truth-values across a given language's atomic propositions (Carnap, 1956). From there, the development of fullfledged possible worlds semantics inspired an arguably 'un-Humean' leap to replacing state descriptions conceived of as linguistic entities with analogous metaphysical entities (of various kinds) which were argued to 'truth-make' modal claims. Yet even in Lewis' most extreme form of modal realism (Lewis, 1986), Modal Combinatorialism played a powerful role in his influential (selfidentified 'Humean') analysis of laws of nature as mere patterns of regularity across subsets of possible worlds, where possible worlds are defined wholly in terms of infinite and unrestricted permutations of simple objects and properties: 'just one little thing, and then another' (Lewis, 1986, ix). At that point the view significantly shaped analyses of physicalism and supervenience through 
the 1970s and 1980s. Armstrong (1989, especially pp. 116-8) also made use of Modal Combinatorialism to construct an ontology of allegedly discrete atomic states of affairs, while at the same time, ironically, Lewis used it to argue that Armstrong's concept of a state of affairs - in apparently requiring particulars and universals to accompany one another necessarily - was subject to a distressingly arbitrary ontological restriction (Lewis, 1992).

With Hume's scepticism regarding real (i.e. irreducible) necessary connections between distinct existences so deeply ingrained, it is not surprising that the possiblity of perceivable necessities has not been on the table. But there is a further obstacle. What Hume means by 'distinct' cannot be fully understood apart from his theory of perception and associated epistemology, which are also highly influential in contemporary philosophy. To this we now turn.

\section{Humean theory of perception: passive}

Yablo (1993) sketches the kind of 'broad-brush' counterargument commonly given against the perceivability of necessity:

... perception itself brings word of sensory mechanisms seemingly hard at work monitoring external conditions. By contrast, "we do not understand our own must-detecting faculty." Not only are we aware of no bodily mechanism attuned to modal aspects, it is unclear how such a mechanism could work even in principle (Yablo, 1993, pp. 3-4). ${ }^{10}$

The talk of 'mechanism', 'monitoring' and 'attunement' indicates a certain view of perception, as a passive process something like a thermometer's response to temperature. The environment acts, the mechanism responds automatically. That is not the only possible approach. Older Aristotelian and Rationalist traditions took a more active view of perception (Ebert, 1983; Spruit, 2008; Hatfield, 2007); so does much modern perceptual psychology, as we will see later. The view Yablo describes descends from Hume. ${ }^{11}$

It is well known how Hume's account of perception begins with causal contact between our senses and objects both 'internal' and 'external', which generates impressions and ideas. Impressions may spring from 'outside the mind' (impressions of sensation) or 'inside the mind' (impressions of reflexion), but the latter solely combine previous impressions of sensation, which are the building blocks of all thought. To emphasise the mechanical, passive nature of reflexion, Hume likens it too to perception - remembering is essentially a perception of ideas that are 'weaker' and 'less vivid'. In fact Hume notes (following Locke, Essay, 1689/1979, IV.i.2-3) that there is an important sense in which all mental activity is perception: 'To hate, to love, to think, to feel, to see; all this is nothing but to perceive' (Treatise 1, II, vi). ${ }^{12}$

Hume's epistemic passivity also emerges in his denial of abstract ideas. $\mathrm{He}$ defines these as ideas which are general in that at least some of their 
determinable properties lack determination (a 'general triangle' is neither isosceles or scalene, a 'general man' has no particular height or age). Allowing abstract ideas would render the mind active since it would need to choose which determinables to abstract from and then perform an act of abstraction. Hume sees their denial as a properly naturalistic position to take against scholastic obscurantism, since a major plank of pre-modern epistemology was the mind's grasp of Aristotelian real essences such as 'man in general'.

The widespread philosophical influence of this view of perception today is nicely illustrated by a recent argument in the philosophy of mathematics concerning whether sets can be perceived. Maddy proposes that, when I open a refrigerator and look at three eggs, I not only perceive the curved white surfaces, I perceive that the surfaces form three eggs and in so doing I perceive a set of three eggs. Balaguer counter-argues as follows:

... we cannot perceive these sets. I begin by asking whether we can perceive the structural difference between an aggregate and a set. ... Since the set and the aggregate are made of the same matter, both lead to the same retinal stimulation ... But ... then the perceptual data about the set is identical to the perceptual data about the aggregate. Thus, we cannot perceive the difference between the aggregate and the set. But since it is pretty obvious that we can perceive the aggregate, and since there is a difference between the aggregate and the set, it follows that we cannot perceive the set (Balaguer, 1994, p. 104; Maddy's original argument in Maddy, 1990, pp. 60-61).

The move from 'we receive only one retinal stimulation' (from both the aggregate and the set) to 'we cannot perceive the difference between the aggregate and the set' assumes that perception is a function of single sensory impressions transformed without residue into single ideas. That expresses a passive view of perception since it rules out the possibility that a relatively low-level visual process might register the egg aggregate and a higher level, more active, process recognise the set. (The latter is arguably an empirical description of the mind's forming an abstract idea.) It is the fact that Balaguer does not feel the need to justify this view of perception that indicates the success of Humeanism on this score.

\section{Humean theory of perception: atomist}

Hume's theory of perception is also importantly atomistic in that any distinguishable ideas effectively constitute separate 'objects' (whatever that yet-unexplicated term means in the broader context of his philosophy). For instance, when we distinguish shape from colour in an object such as a white cube, it is not that we use reason to distinguish its colour and shape as abstract ideas (of whiteness and cube-hood). ${ }^{13}$ Rather, Hume claims that 
what we do is imagine black cubes and white globes. Without such a literal, quasi-perceptual forcing apart of ideas we cannot distinguish them, though we might think we can - a cause of much confusion and wasted time in philosophy. ${ }^{14}$ We now have a criterion of distinctness to use in evaluating Hume's maxim. Let's call it Hume's Separate Imaginability Criterion of Distinctness. It essentially consists in the denial that, when distinguishing ideas and objects, one might abstract (an idea) without separating (it into a distinct object).

Let us return to Hume's Modal Combinatorialism, which we now see that Hume wishes to apply to all ideas, qua building-blocks of his epistemology. It is important to distinguish two definitions of combinatorialism. The first, 'top-down' definition claims that any whole can be decomposed into some collection of atomic parts of certain specified kinds. ${ }^{15}$ The second, 'bottom-up' definition holds that given some collection of atomic parts, any combination of them is possible. We suggest that Hume is committed to the second, stronger, kind of combinatorialism.

Fogelin points out that Hume himself raised an objection to this claim, his failure to answer which has scandalized his readers (Fogelin, 1984). Hume admits that we could obtain knowledge of a missing shade of blue from knowledge of actually perceived adjoining shades, a feat that apparently requires some necessary relations among shades of blue. Fogelin writes:

$\ldots$ an atomist in perceptual theory would deny the existence of any structure below the lowest level of the perceptual ontology and thus would hold that each simple impression is a pure content standing in no systematic relationship to any other simple impressions except for being qualitatively identical with it or simply qualitatively different from it ... Hume's discussion of the missing shade of blue shows that he does not accept such a theory of perception ... (Fogelin, 1984, p. 268).

If we are able to imagine the missing shade of blue given its darker and lighter neighbours, it seems that we are able to decompose seen blues into more fundamental concepts such as hue and darkness, with their own transitive logic. ${ }^{16}$ The existence of such a necessary structure would violate the universal mutual compossibility of distinct ideas insofar as it is impossible for A to be darker than B, B darker than $\mathrm{C}$ and $\mathrm{A}$ not darker than $\mathrm{C}$. But it also violates Hume's stated dictum that '... nothing is contrary but existence and non-existence'. We suggest, as have several commentators, that what Hume says about the missing shade of blue is ambiguous and inconclusive, and that Hume's views at this point suffer overall inconsistency. ${ }^{17}$ Like Hume's metaphysical combinatorialism, his atomism about perception has settled deep in analytic philosophy, where it may be most clearly seen in early attempts to 'construct' external reality from individualized sensations. ${ }^{18}$

We have now established a certain general picture of perception as a passive registering of objects that are all atomistic ('loose and separate', in 
another of Hume's famous phrases), and outlined how this suggests an epistemology according to which knowledge of necessity cannot enter the mind through the senses, which in turn produces a metaphysics according to which 'nothing is contrary but existence and non-existence'. In the next section we hold this general picture up to contemporary science and suggest it is wanting, before returning to our examples of perceiving necessities in mathematics.

\section{Cognitive psychology's counterexamples to Humean theo- ries of perception}

There is no lack of contemporary research which undermines both the passivity and atomism of the Humean view of perception. With respect to the passivity, it has become clear that the brain's perceptual functioning is far from Hume's simple copying of impressions into ideas. Rather, the brain is continually comparing its input against complex sets of prior (possibly learned) expectations, using mismatches for purposes of self-correction. Gregory (1980) advanced the idea that all perceptions should in fact be understood as hypotheses which are then checked against further incoming data, ${ }^{19}$ and this idea has lately been gaining ground (e.g. Hohwy, 2010; Clark, 2013).

With respect to the atomism, current consensus appears to be that most key aspects of visual perception are attained not only - as a Humean would expect - via 'bottom-up' accumulation of masses of low-level visual impressions, but also by directly registering high-level structural properties. This applies at least to colour, contour, size, and relative motion (Kaufman, 1974). Moreover, those researchers who understand perception as hypothesis have shown that not only is the mind organised sufficiently holistically to support 'top-down predictions', it operates this way at a number of distinct functional levels which are richly inter-related, producing '.. a cascade of cortical processing events in which higher-level systems attempt to predict the inputs to lower level ones on the basis of their own emerging models of the causal structure of the world' (Clark, 2013). ${ }^{20}$

A particularly nice anti-atomistic example is the perception of symmetry. This is a high-level structural property. In fact the necessary truth perceivable in Figure 1 draws directly on symmetry-perception in recognising the sameness of the rows and columns, while the symmetry of the square and of the diamond plays a key role in recognising the necessary truth shown in Figure 2.

As an example of the many scientific results regarding symmetry perception, we take the differences between perception of bilateral symmetry about a vertical axis and other symmetries (such as symmetries about other axes, or repetitions of shapes in friezes). Vertical bilateral symmetry is perceived much more rapidly. It is said to be 'preattentive' in that it can be perceived 
when the stimulus array is presented for less than 160 milliseconds - less than the time the brain takes to attend to anything. It is possible to perceive vertical bilateral symmetry in simple random shapes presented for only 25 milliseconds (Wagemans, 2002). These precise measurements confirm experimentally what is obvious perceptually in figures such as Figure 4: that vertical bilateral symmetry has an immediate and salient 'look' compared to symmetry about an oblique axis.

This effect is what underlies the fact that a square is perceived as a different shape from a diamond, as in Figure 2 above. Though the two are congruent, their symmetries are differently related to the environmental horizontal and vertical axes.

These results show that symmetry perception combines what Hume alleges to be impossible. Symmetry is a global property of an array: it is a relation between parts, not a property of any one part. So perception of it cannot be atomic. Nor can it be passive, since epistemic activity is needed to compare the parts in this particular way. Yet it is immediate - as immediate as any perception can be, at least in the case of vertical bilateral symmetry - and unquestionably pre-reflective, as the perception occurs below the timescale on which reflection operates. The deeply automatic and pre-reflective nature of symmetry perception is confirmed by its appearance in animals, including very simple ones. Perception of symmetry has been demonstrated in apes, dolphins and birds; it is possible to train bees to prefer either symmetrical or

(a)
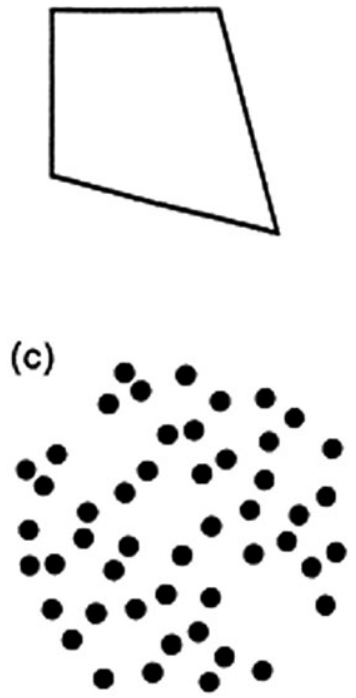
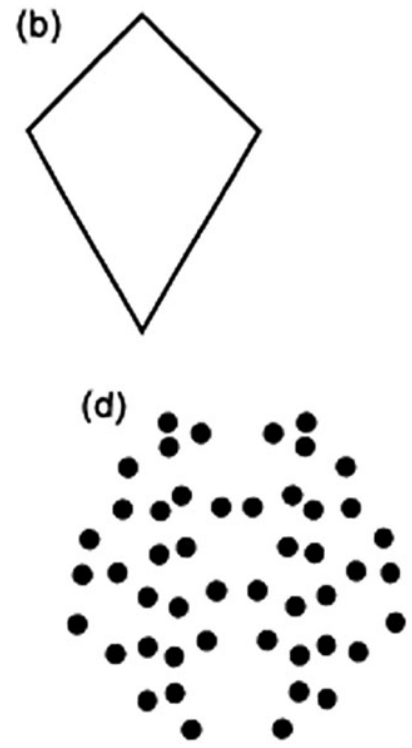

Figure 4 Vertical-axis Symmetry (b and d) Contrasted with other Axes (a and c). ${ }^{21}$ 
asymmetrical patterns, but the preference for symmetry comes more naturally to them (Giurfa et al., 1996). Bees are animals innocent of reflection, and it is hard to believe they deal in 'relations of ideas', in Hume's sense. They just see.

Such examples not only refute Humean atomism about perception, but supply an answer to one of the objections to the thesis that we perceive necessity that was mentioned in Section 1. Might not the apparent immediacy of our perception that $2 \times 3=3 \times 2$ be a cover for some processes of unconscious inference? It is true that the phenomenology is against it, since our insight seems immediate, but then introspective phenomenology is widely suspected of making many errors. Might not the feeling of immediacy be an illusion?

We now see that the existence of unconscious inferences is no objection to a process's being perceptual, since perception typically involves unconscious inferences. (Recall that the definition of perception given in Section 1 only ruled out 'deliberate mental actions such as imagining or explicit reasoning'.) The empirical results discussed above suggest that if perception could not involve unconscious inference, then we would be unable to perceive symmetry (on the basis of sameness of parts).

It might be protested that this understanding of perception still raises the question of which inferences are performed in perception and which are left to 'higher' levels of cognition (and here by 'higher', following our definition of perception in $\S 1$, we mean more deliberate, or more accessible to deliberation). It might be worried that without such an account we cannot dismiss the possibility that the necessities apparently perceived in section $\S 1$ are in principle beyond the inferential capacities of perception.

There is currently no agreed answer to this question. However, valuable light has been recently cast on it by an extensive philosophical discussion of Fodor's 'modularity of mind' thesis (Robbins, 2009). Fodor pointed to well-known perceptual phenomena such as the Müller-Lyer illusion (Figure 5), where two lines persist in appearing to be of different lengths even when the subject knows they are the same.
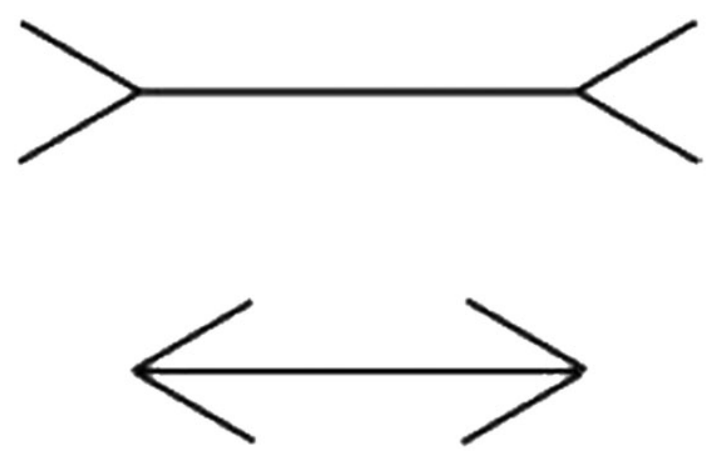

Figure 5 The Müller-Lyer Illusion. 
Visual comparison of two lines requires an unconscious inference: to say that the lines 'look different' in length is to say that the comparison takes place within perception. But the inference is 'informationally encapsulated', the visual 'module' being not 'cognitively penetrable' by the beliefs acquired for example by measurement - of the higher cognitive faculties.

Later work (e.g. Vetter and Newen, 2014) has tended to show that perception is to some small degree penetrable by deliberative cognition. Theory can sometimes override lower-level perceptions, whence the difficulty of spotting typos. But that is not significant for the present argument. What is important (and - we hope to show - obvious) is that the visual and other perceptual modules have inherent capacities to perceive complex relational properties, below the level of the higher cognitive faculties, and to deliver the results whole 'upstairs'.

\section{How our examples escape the Humean theses}

Let us return to our examples of Section 1 - prima facie clear cases of perceiving necessity - and reexamine them in the light of what we have learned about Hume's maxim, his theory of perception, and the true capacities of perception. We begin with Figure 1:

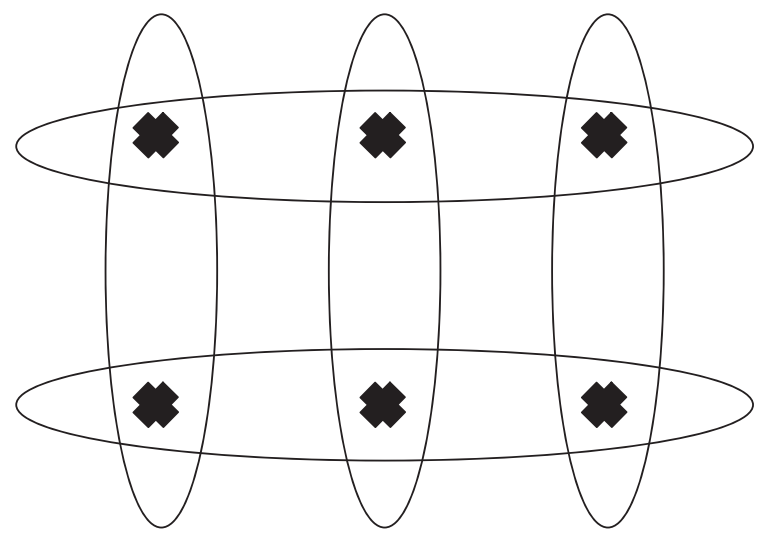

This diagram demonstrates a necessary truth. Does it demonstrate a necessary connection between distinct existences? Well, what exactly are the 'existences' here, which the Humean would wish to deny are necessarily connected? For a very natural objection ${ }^{22}$ to our view asks what objects could possibly be perceived in the case of perception of necessity such as is claimed to exist in this case. If I see that the ground is wet, I see the ground and its watery surface. In perceiving that $2 \times 3=3 \times 2$, what objects do I perceive? How can my knowledge of this necessary truth be perceptual unless I can perceive mathematical objects? 
We will suggest that the Humean has three choices - all problematic. We will then sketch a fourth, non-Humean view, which we favour.

(i) Physical Mark View: Here we might understand the relevant 'objects' or existences to be 6 stars and 5 ovals (and further combinations of these, for example the 5 oval + star combinations), exactly as scribed on the page. This appears to be a natural choice in terms of the organisation of our visual field. Recall the Humean Separate Imaginability Criterion of Distinctness: we can imagine each shape existing on its own on the page. But then it is false that there are no necessary connections between these objects as positioned in Figure 1. For instance, one cannot remove stars from the vertical ovals without thereby removing them from the horizontal ovals. Interpreted thus, then, Hume's maxim is simply incorrect.

(ii) Abstract Object View: On the other hand, we might take the necessary connection just noted as a sign that our diagram does not display a truth about physical marks but about some reality that is more purely mathematical or 'abstract'. Under this interpretation, the relevant objects/existences might be identified as (three) ' $2 \mathrm{~s}$ ' and (two) ' $3 \mathrm{~s}$ '. These abstract objects are arguably not distinct from one another. For instance we might plausibly understand 2 as made up of 'two ones' and 3 as made up of 'three ones', and thus see 2 as a proper part of 3. At this point, then, Hume might defend his maxim by stating that Figure 1 solely expresses relations between ideas, which he never meant to claim were distinct existences (his famously sharp distinction between matters of fact and relations between ideas is precisely meant to teach this), so it is not a counterexample to his maxim.

But there is something unsatisfying here. It seems puzzling to claim that we can gain mathematical knowledge, as we clearly can, by examining Figure 1, and yet that mathematical objects are entirely separate from our experience. How is it then that the diagram is so effective? Furthermore, now Hume's maxim seems to beg the question. He seems to be arbitrarily ruling out that we perceive the kinds of existences between which necessary connections clearly hold, by labelling them as 'mere ideas'. He seems happy to apply a Separate Imaginability Criterion of Distinctness in the causal case (the billiard balls), where it rules that the motions of the two balls are distinct since one can be imagined apart from the other, and thereby justifies Hume's favoured intuitions about causality. But in Figure 1 one may equally imagine each oval + star object existing on its own. Yet as noted, these objects as assembled in Figure 1 do seem to have necessary connections between them. If Hume then argues that the stars and ovals cannot be distinct existences precisely because of these 
necessary connections, his maxim effectively becomes: 'there are no necessary connections between distinct existences, which are those existences between which there are no necessary connexions'. It is then devoid of philosophical content.

(iii) 'Both' View: Given these problems with both the Physical Mark view and the Abstract Object view, a Humean might attempt to compromise by combining the two, stating that the best account of the objects represented by Figure 1 is that there are ovals and stars and $2 \mathrm{~s}$ and $3 \mathrm{~s}$. However such a compendium raises tricky questions of the relationship between the physical marks and the abstract objects. It would seem to treat the physical marks and the abstract objects as existences distinct from each other, in which case, according to Hume, they must be separable. In that case, why include the stars and ovals in the diagram at all? Why not lose the physical marks, keep the twos and threes and draw the mathematical moral straight from them? This is obviously impossible in Figure 1, thus the view itself risks incoherence.

(iv) Partial Identity View: This final remark points the way to a fourth interpretation which we believe is closest to the truth. This view is 'hybrid (between the Physical Mark and the Abstract Object views) ... but not both'. Rather than understanding physical marks and abstract objects as separate existences, it is more accurate to understand abstraction as a mental process whereby we perceive in the diagram as it exists on the page certain partial identities. What does this mean? Just that 'twoness' may be abstracted from this:

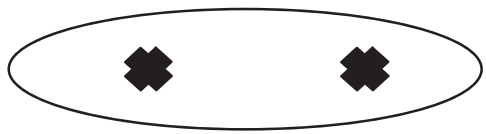

while precisely not being separable from it as a distinct object. This kind of 'distinction of reason' is of course exactly what Hume's epistemology rules out as impossible. Yet abstraction without separation is essential for all structural reasoning, since a structure cannot exist without objects to structure. And structural reasoning is surely a significant part of mathematics. One might even argue that all necessary reasoning is structural (Legg, 2012).

This is our answer to the objection that asks what objects could possibly be perceived in the case of perception of necessity such as is claimed to exist in the $2 \times 3=3 \times 2$ case. We do not perceive, or need to perceive, abstract numbers or operators. We do need to perceive mathematical properties of 
physical objects (symmetry, divisibility, alternation, continuity and so on), but that is possible by ordinary perception. We can perceive that the ground is wet, and we can perceive just as directly that that ground is divisible, or parted. In the array of crosses, we can perceive that a part is a cross, that it is a cross congruent to a cross elsewhere in the array, that the array has parts in various ways: as rows and columns of crosses. As there are necessary relations between those different divisions into parts, there is no obstacle in principle to perceiving those relations or their necessity.

Of course, perception of the structural partial identities described above is necessary but not sufficient for perceiving the necessity of $2 \times 3=3 \times 2$. But there is only one further thing that needs to be recognised in this case. This is the full-fledged identity between the two (abstractable but not separable) structures realised by the diagram: namely $2 \times 3$ (two rows of three stars) and $3 \times 2$ (three columns of two stars). In other words, once the two-row/ three-column structure is perceived in Figure 1, all that is needed to perceive $2 \times 3=3 \times 2$ is the recognition that these are two decompositions of the same whole. There is no difficulty in perceiving that. The six stars and their two decompositions are plain for the eye to see. ${ }^{23}$ Thus we see that the two sides of the equation are equal, and that variants such as $2 \times 3=3 \times 3$ are impossible.

Can a similar analysis be extended to our geometrical Figure 2?

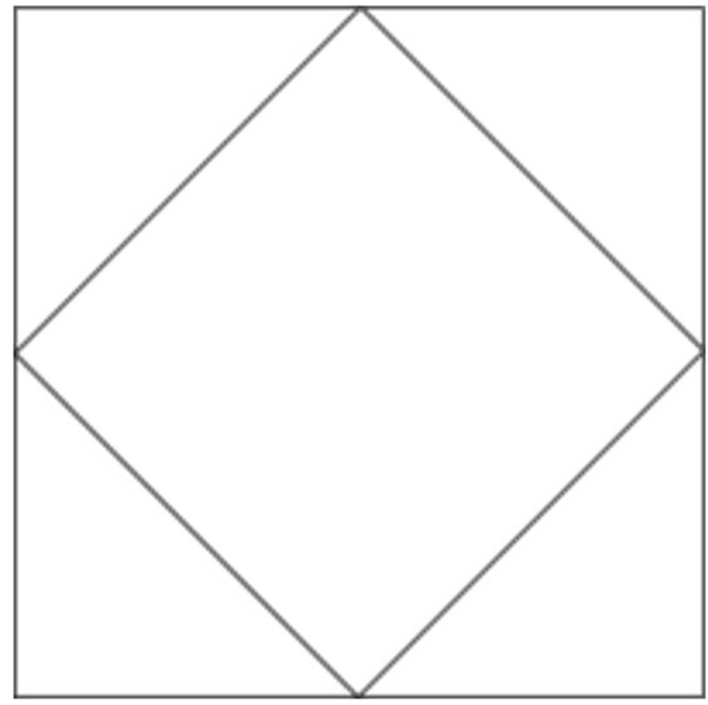

Here the result that the diamond is half the area of the square comes from recognizing that the area of each quarter of the diamond equals the area of the triangle outside it. All that is required for this is perception of the symmetry of the figure. What are this diagram's relevant objects? Again, we might attempt to define a Physical Mark view that the relevant 
objects are 1 square, 1 diamond and 4 triangles, as inscribed on the page. However here in the non-discrete field of geometry we can see even more clearly that this interpretation is not correct. It was noted earlier that diagrams as instantiated frequently contain imperfections which perception 'rectifies'. Thus, the necessary truth perceived here (that the diamond is half the area of the square) might not even be true of Figure 2, if its shapes were carefully measured. ${ }^{24}$

On the other hand an Abstract Object view would say that the real objects of the diagram are some kind of general square, diamond and triangle. And yet despite that, somehow, viewing the physical marks helps us to perceive the necessary truth. Why is this? Once again, our favoured account rests on the perceiving mind's ability to abstract from the diagram (but also at the same time appropriately reunite mentally) overall structural features which are sufficiently general to rectify minor diagrammatic inaccuracies where necessary.

Figure 3 concerns transfinite arithmetic. Hume is famously dismissive of infinity: because our ideas of quantity cannot be divided indefinitely, he argues, neither can quantity itself. ${ }^{25}$ For similar reasons, Humeans such as Wittgenstein take a sceptical view towards 'rulefollowing' across infinite sequences. And yet this proof in transfinite arithmetic works, and its work is heavily dependent on perception. Our diagram shows in some general sense how one-one matching between natural and rational numbers can proceed across an infinite series. Although we do not perceive the whole series, we see enough recursive structure to be sure the proof is correct. Hume claimed, following Berkeley, that any supposed abstract idea is nothing but a particular, entirely determinate idea that annexes itself to a general term, and associates with other particular ideas which it resembles in relevant ways. But that story clearly does not fit this case, since it would require either a particular, determinate idea which is infinitely complex, or an infinite number of them.

\section{Perceiving necessity versus platonist intuition}

A different objection to our thesis that necessity may be perceived derives from philosophical Platonism, which has modern adherents in philosophers such as James Robert Brown and Elijah Chudnoff. According to this view, there is a sharp distinction between sensory perception and so-called 'intellectual perception'. Mathematical insight falls into the latter category, so although we may have 'intuition' of the realm of Forms (or - as more commonly known these days - abstract objects), there is not, and cannot be, any perception of necessity in the physical world. Such views are obviously 
premised on a sharp metaphysical distinction between this world where, as Humeans think, there are no necessities, and a Platonic realm of the abstract, where all necessities reside. As Chudnoff explains:

Abstract reality encompasses the necessary, normative, infinite and abstract as in non-spatiotemporal and causally inert. Mathematics, metaphysics and morality are about it. Concrete reality encompasses the contingent, non-normative, finite and concrete as in spatioand/or temporal and/or causally efficacious. Physics, psychology and history are about it (Chudnoff, 2013, p. 11; similar in Brown, 2008, pp. 13-14).

Such an argument rests on a rigid dichotomy between the concrete and the abstract whereby all necessity lives in the acausal abstract realm, while the causal physical realm is all contingency. Somewhat ironically, given the otherwise divergent nature of their philosophies, both Hume and Plato subscribe to this dichotomy. They merely differ in that whereas Hume's treatment of relations between ideas is sceptical, seeking to reduce such truths to (relatively trivial) stipulated verbal definitions, Plato makes such relations the basis for a transcendent metaphysical realm.

A key purpose of this article is to call this dichotomy into question. The last section showed that to regard a mathematical diagram such as Figure 1 as somehow representing both concrete and abstract objects as separate existences conflicts with our phenomenology of gaining mathematical knowledge from such diagrams. When examined, the diagram's system of physical marks seems not to be possessed of solely contingent properties - since as noted one cannot alter the arrangement of stars in the vertical ovals without altering that in the horizontal ovals - and the relevant abstract objects ( $2 \mathrm{~s}$ and $3 \mathrm{~s}$ ) are not clearly separable from them. We therefore urge that the only way to account for the phenomenology of understanding the proof in Figure 1 is to understand its relevant mathematical concepts to be abstractable from the physical mark. This is not an ontological reification but an epistemic process. One might go so far as to say that the whole concept of an 'abstract object', which has such wide currency in contemporary philosophy of mathematics, constitutes a mistake predicated on not understanding that one can abstract without separating. ${ }^{26}$ Thus, in Euler's famous proof that one could not walk over all the bridges of Königsberg once without walking over at least one of them twice: the impossibility applies (strictly and literally) to real paths over real bridges, not merely to some abstract model of them (Franklin, 2014, ch. 5). In that way, our account might be understood as counterposing an Aristotelian realist account of mathematical objects to the Platonism which features so prominently in contemporary philosophy of mathematics as realism's representative. ${ }^{27}$ 


\section{Conclusion}

We can perceive necessary truths. In such perception the mind is not passive and atomistic, but active and integrated - simultaneously abstracting, and recognising identities amongst, structural features of what is perceived, in ways that confer real insight. If we were to work out the consequences of this insight for epistemology, where would it take us? We suggest that at this point it could be extremely helpful to look back to rationalist and scholastic views largely left behind by Anglo-American philosophy, which has so admired Hume and Plato. These older views taught that certain knowledge may be attained from ideas that are sufficiently clear and distinct. Our examples arguably show clear and distinct perceptions giving rise to direct knowledge of mathematical necessities. The onus is on contemporary epistemology to either assimilate these examples to its received ideas, or to explain them away.

\section{Philosophy Programme \\ University of Waikato}

\section{School of Mathematics and Statistics University of New South Wales}

\section{NOTES}

1 A claim reminiscent of Aristotle in the Posterior Analytics, in particular Bk II, ch. 2.

2 An example is the claim that a function which is continuous is differentiable almost everywhere: visual intuition suggested this was true, but it is false. This example is nicely discussed in Giaquinto, 2007, pp. 3-4; and Mumma, 2010, pp. 3-4.

3 By permission of Oxford University Press.

4 That would be to agree with the naïve view that technical drawing is the same subject as geometry, but more accurate. David Sherry notes, '... more sophisticated empirical observations, such as measurement, play no role in diagrammatic reasoning - even if they can be useful for suggesting theorems' (Sherry, 2009a, p. 62). He points out that under the right circumstances a diagram may even be used to prove of a mathematical object properties which are clearly false of the diagram.

5 Cantor to Dedekind, 29 June 1877 . The result referred to is the sameness of cardinality of the unit interval and the unit square, of which Cantor gives a partly visual proof (Gouvêa, 2011). The rigor of 'seeing' in a similar proof is defended in Azzouni, 2013.

6 Image created by Maria Miller, reproduced with permission from http://www. homeschoolmath.net/teaching/rational-numbers-countable.php

7 Further on seeing truths in diagrams that represent continuation to infinity in (Feferman, 1998, 2012).

8 Advanced players will notice that the three distinct implications just listed also have necessary connections between them. Many more complex mathematical necessities about billiard ball trajectories are listed at http://mathworld.wolfram.com/Billiards.html .

9 \$1.12: 'Each item can be the case or not the case while everything else remains the same' (Wittgenstein, 1961). 
10 The internal quote is from Blackburn, 1986, p. 52; Yablo is actually considering the relation between conceivability and possibility, but the issue of naturalism and modality is the same as in our case.

11 There is some ancestry in earlier empiricism: '... the reception of the Ideas of light, roundness, and heat, wherein I am not active but barely passive, and cannot in that position of my Eyes, or Body, avoid receiving them.' (Locke, Essay 2.21.72).

12 See also Enquiry, p. 152 (Hume, 1748/1975).

13 This process was sometimes referred to in the medieval period as 'prescinding', 'prescission' or 'abstraction' of qualities from a given object. (Weinberg, 1965, part 1)

14 '... if the figure be different from the body, their ideas must be separable as well as distinguishable; if they be not different, their ideas can neither be separable nor distinguishable. What then is meant by a distinction of reason, since it implies neither a difference nor separation? (Treatise, 1, I, vii).

15 This seems to be what is meant by 'combinatorialism' in philosophy of language and related disciplines.

16 We noted that Hume largely follows Locke in his passive theory of perception and in seeking to construct 'an entirely perception-driven epistemology'. Locke also tackles the issue of 'colour logic', and from whence, in such a framework, it might be derived. He writes: 'For when we know that white isn't black, what do we perceive other than that these two ideas don't agree?' (Essay, IV.i.2) But here the phrase 'don't agree' hides a crucial elision - from 'black and white are different' to 'black and white are contrary' - an elision to which Locke's raw empiricism is arguably not entitled. The authors are grateful to Max Cresswell for pressing us to work out this point.

17 Fogelin finishes his remark above by noting '... it is not easy to find a clear statement of [Hume's] positive views on these matters.'

18 Russell's logical atomism in at least one of its phases aimed to analyse the basic concepts of physics in terms of perceptual simples such as patches of colour and auditory notes (Russell, 1914; Klement, 2009, sect. 3), and Carnap's Aufbau continued the project.

19 See also (Gregory, 1970, 1998). Gregory attributes the original idea to Helmholtz. Influential intermediary work was done by MacKay (1956) and Neisser (1967).

20 Accepting the inferential nature of perception does not lead to any relativist thesis of the 'theory-ladenness of perception', for reasons explained in Fodor, 1990, pp. $238-249$.

21 Figure from Wenderoth, 1996, reprinted with permission from Elsevier; the effect is demonstrated in 4-month-olds (Bornstein and Krinsky, 1985).

22 Raised by an anonymous referee. See also the field-defining critique of Benacerraf, 1973.

23 In seminar presentations of this material, attempts have been made to argue that insofar as the partial identities must be abstracted and therefore perceived separately (constitute examples of 'seeing as', in Wittgensteinian terms), this means that the full-fledged identity cannot be accessed solely via perception but must rely on memory or deliberate inference to at least some degree. It cannot be seen at a glance. We reject this criticism on phenomenological grounds.

24 Again, (Sherry, 2009a) is useful here, noting that in fact geometrical diagrams function via stipulation as much as by observation. In Fig. 3 the equality of the four triangles, the perfect straightness of the lines, and other matters are taken to be implicitly stipulated.

25 Hume, Treatise, 1, II, v, p. 52; Hume has been roundly criticised for this, e.g. Flew, 1976; Fogelin, 1985; Franklin, 1994; Jacquette, 2002. For a more sympathetic reading, see De Pierris, 2012. See also Sherry, 2009b, for an original blurring of Hume's distinction between relations of ideas and matters of fact in a discussion of applied mathematics.

26 The many problems of the standard conception are explained in Rosen, 2012.

27 For a extensively worked-out recent account of such Aristotelianism in mathematics, see Franklin, 2014. 


\section{REFERENCES}

Armstrong, D. (1989). A Combinatorial Theory of Possibility. Cambridge: Cambridge University Press.

Azzouni, J. (2013). "That We See That Some Diagrammatic Proofs Are Perfectly Rigorous," Philosophia Mathematica 21(2), pp. 323-338.

Balaguer, M. (1994). "Against (Maddian) Naturalized Platonism," Philosophia Mathematica 2(2), pp. 97-108.

Benacerraf, P. (1973). "Mathematical Truth," Journal of Philosophy 70(19), pp. 661-79.

Blackburn, S. (1986). 'Morals and Modals,' in his Essays in Quasi-Realism. New York: Oxford University Press, pp. 52-74.

Bornstein, M.H. and Krinsky, S.J. (1985). "Perception of Symmetry in Infancy: The Salience of Vertical Symmetry and the Perception of Pattern Wholes," Journal of Experimental Child Psychology 39(1), pp. 1-19.

Brown, J. R. (2008). Philosophy of Mathematics: A Contemporary Introduction to the World of Proofs and Pictures, $2^{\text {nd }}$ edn. London and New York: Routledge.

Carnap, R. (1956). Meaning and Necessity: A Study in Semantics and Modal Logic. Chicago, IL: University of Chicago Press.

Catton, P. and Montelle, C. (2012). "To Diagram, to Demonstrate: To Do, To See, and To Judge in Greek Geometry," Philosophia Mathematica 20(1), pp. 25-57.

Clark, A. (2013). "Whatever Next? Predictive Brains, Situated Agents, and the Future of Cognitive Science," Behavioral and Brain Sciences, 36(3), pp. 181-204.

Chudnoff, E. (2013). Intuition. Oxford, Oxford University Press.

De Pierris, G. (2012). "Hume on Space, Geometry, and Diagrammatic Reasoning," Synthese 186(1), pp. 169-189.

Ebert, T. (1983). "Aristotle on What is Done in Perceiving," Zeitschrift für Philosophische Forschung 37(2), pp. 181-198.

Feferman, S. (1998). 'Mathematical Intuition vs Mathematical Monsters,' Twentieth World Congress of Philosophy, Boston, MA.

Feferman, S. (2012). “And So On ...: Reasoning with Infinite Diagrams," Synthese 186(1), pp. 371-386.

Flew, A. (1976). 'Infinite Divisibility in Hume's Treatise,' in D. Livingston and J. King (eds) Hume: A Re-evaluation. New York: Fordham University Press, pp. 257-69.

Fodor, J. A. (1990). A Theory of Content and Other Essays. Cambridge, MA: MIT Press.

Fogelin, R. (1984). "Hume and the Missing Shade of Blue," Philosophy and Phenomenological Research 45(2), pp. 263-271.

Fogelin, R. (1985). Hume's Skepticism in the Treatise of Human Nature. London: Routledge and Kegan Paul.

Franklin, J. (1994). "Achievements and Fallacies in Hume's Account of Infinite Divisibility," Hume Studies 20(1), pp. 85-102.

Franklin, J. (2000). 'Diagrammatic Reasoning and Modelling in the Imagination: The Secret Weapons of the Scientific Revolution,' in G. Freeland and A. Corones (eds) 1543 and All That: Image and Word, Change and Continuity in the Proto-Scientific Revolution. Dordrecht: Kluwer, pp. 53-115.

Franklin, J. (2014). An Aristotelian Realist Philosophy of Mathematics: Mathematics as the Science of Quantity and Structure. Basingstoke: Palgrave Macmillan.

Giaquinto, M. (2007). Visual Thinking in Mathematics. Oxford: Oxford University Press.

Giurfa, M., Eichmann, B. and Menzel, R. (1996). "Symmetry Perception in an Insect," Nature 382, pp. $458-461$.

Gouvêa, F. Q. (2011). "Was Cantor Surprised?," American Mathematical Monthly 118(3), pp. 198-209. 
Gregory, R. L. (1970). The Intelligent Eye. London: Weidenfeld and Nicolson.

Gregory, R.L. (1980). "Perceptions as hypotheses," Philosophical Transactions of the Royal Society of London. Series B, Biological Sciences 290(1038), pp. 181-197.

Gregory, R. L. (1998). Eye and Brain. Oxford: Oxford University Press.

Hatfield, G. (2007). 'Rationalist Theories of Sense Perception and Mind-Body Relation,' in A. Nelson (ed.) A Companion to Rationalism. Oxford: Blackwell.

Hohwy, J. (2010). 'The Hypothesis-Testing Brain: Some Philosophical Applications,' in W. Christensen, E. Schier, and J. Sutton (eds) ASCS09: Proceedings of the 9th Conference of the Australasian Society for Cognitive Science. Sydney: Macquarie Centre for Cognitive Science.

Hume, D. (1739-40 [1978]). A Treatise of Human Nature, L. A. Selby-Bigge (ed.) Oxford: Oxford University Press.

Hume, D. (1748) [1975]. Enquiry Concerning Human Understanding, L.A. Selby-Bigge, ed.; $3^{\text {rd }}$ edn rev. P.H.Nidditch. Oxford: Oxford University Press.

Jacquette, D. (2002). "Hume on Infinite Divisibility and the Negative Idea of a Vacuum," British Journal for the History of Philosophy 10(3), pp. 413-435.

Kaufman, L. (1974). Sight and Mind: An Introduction to Visual Perception. Oxford: Oxford University Press.

Klement, K. (2009) (original version 2005). 'Russell's Logical Atomism,' in E.N. Zalta (ed.) Stanford Encyclopedia of Philosophy.

Legg, C. (2012). "The Hardness of the Iconic Must: Can Peirce's Existential Graphs Assist Modal Epistemology?,", Philosophia Mathematica 20(1), pp. 1-24.

Lewis, D. (1986). On the Plurality of Worlds. Oxford: Blackwell.

Lewis, D. (1992). "Armstrong on Combinatorial Possibility," Australasian Journal of Philosophy, 70, pp. 211-224.

Locke, J. (1689) [1979]. An Essay Concerning Human Understanding, P. H. Nidditch (ed.) Oxford: Clarendon Press.

Macbeth, D. (2005). Frege's Logic. Cambridge MA: Harvard University Press.

Macbeth, D. (2009). "Meaning, Use and Diagrams," Etica \& Politica / Ethics \& Politics XI(1), pp. 369-384.

MacKay, D.M. (1956). 'The Epistemological Problem for Automata,' in C.E. Shannon and J. McCarthy (eds) Automata Studies. Princeton, NJ: Princeton University Press, pp. 235-251.

Maddy, P. (1990). Realism in Mathematics. Oxford: Oxford University Press.

Manders, K. (2008). 'The Euclidean Diagram,' in P. Mancosu (ed.) The Philosophy of Mathematical Practice. Oxford: Oxford University Press.

Mumma, J. (2010). "Proofs, Pictures and Euclid," Synthese 175(2), pp. 255-287.

Neisser, U. (1967). Cognitive Psychology. New York: Appleton-Century-Crofts.

Robbins, P. (2009). 'Modularity of Mind,' Stanford Encyclopedia of Philosophy.

Rosen, G. (2012) (original version 2001). 'Abstract Objects,' in E.N. Zalta (ed.) Stanford Encyclopedia of Philosophy.

Russell, B. (1914) [1918]. 'The Relation of Sense Data to Physics,' in his Mysticism and Logic and Other Essays. London: Longmans, pp. 108-131.

Sherry, D. (2009a). "The Role of Diagrams in Mathematical Arguments," Foundations of Science 14, pp. 59-74.

Sherry, D. (2009b). "Reason, Habit and Applied Mathematics," Hume Studies 35(1 \& 2), pp. 57-85.

Shin, S-J. (2002). The Iconic Logic of Peirce's Graphs. Cambridge, MA: MIT Press.

Spruit, L. (2008). 'Renaissance Theories of Active Perception,' in S. Knuuttila and P. Kärkkäinen (eds) Theories of Perception in Medieval and Early Modern Philosophy. Dordrecht: Springer, pp. 203-224. 
Vetter, P. and Newen, A. (2014). "Varieties of Cognitive Penetration in Visual Perception," Consciousness and Cognition, 27, pp. 62-75.

Wagemans, J. (2002). 'Detection of Visual Symmetries,' in C.W. Tyler (ed.) Human Symmetry Perception and its Computational Analysis. Mahwah NJ: Lawrence Erlbaum, pp. 25-48.

Weinberg, J. R. (1965). Abstraction, Relation and Induction: Three Essays in the History of Thought. Madison WI: University of Wisconsin Press.

Wenderoth, P. (1996). "The Effects of Dot Pattern Parameters and Constraints on the Relative Salience of Vertical Bilateral Symmetry," Vision Research 36(15), pp. 2311-2320.

Wilson, J. (2010). "What is Hume's Dictum, and Why Believe It?" Philosophy and Phenomenological Research 80(3), pp. 595-637.

Wittgenstein, L. (1961). Tractatus Logico-Philosophicus, D. F. Pears and B. F. McGuinness trans. London: Routledge.

Yablo, S. (1993). "Is Conceivability a Guide to Possibility?" Philosophy and Phenomenological Research 53(1), pp. 1-42. 